\title{
Month of Birth Related to Fecundity and Childlessness Among Contemporary Women
}

\author{
Author(s): P. H. Jongbloet, H. M M. Groenewoud, S. Huber, M. Fieder, and N. Roeleveld
}

Source: Human Biology, 79(5):479-490. 2007.

Published By: Wayne State University Press

DOI: http://dx.doi.org/10.1353/hub.2008.0006

URL: http://www.bioone.org/doi/full/10.1353/hub.2008.0006

BioOne (www.bioone.org) is a nonprofit, online aggregation of core research in the biological, ecological, and environmental sciences. BioOne provides a sustainable online platform for over 170 journals and books published by nonprofit societies, associations, museums, institutions, and presses.

Your use of this PDF, the BioOne Web site, and all posted and associated content indicates your acceptance of BioOne's Terms of Use, available at www.bioone.org/page/terms_of_use.

Usage of BioOne content is strictly limited to personal, educational, and non-commercial use. Commercial inquiries or rights and permissions requests should be directed to the individual publisher as copyright holder. 


\title{
Month of Birth Related to Fecundity and Childlessness Among Contemporary Women
}

\author{
P. H. JONGBLOET, ${ }^{1}$ H. M. M. GROENEWOUd,${ }^{1}$ S. HUBER,${ }^{2}$ M. FIEDER,${ }^{3}$ AND \\ N. ROELEVELD ${ }^{1}$
}

\begin{abstract}
To determine the associations of fecundity and childlessness with month of conception and to find a causal mechanism for these associations, we reanalyzed some of our previous data according to the predictions of the seasonal optimal ripening oocyte (SOptRO) and seasonal preovulatory overripeness ovopathy (SPrOO) hypotheses. Prime and minor SOptRO months as well as high-risk, no-risk, and very high risk SPrOO months were defined on the basis of a priori knowledge of the existence of ovulatory and anovulatory seasons in mammals and of the general birth distribution in Europe. The month of birth was assessed among 899 mothers with three or more children and 388 childless women extracted from a $1 \%$ sample of the Austrian population. The women with three or more children were born in excess during the prime and less often during the minor SOptRO months $\left(\chi^{2}=2.81 ; p=0.045\right.$; relative risk $=1.16 ; 95 \% \mathrm{CI}=1.01-1.33)$. This is in line with the SOptRO predictions. The childless women were more frequently born during the highrisk SPrOO months compared to the no-risk months but less often during the very high risk months. The linear trend $\left(\chi^{2}=8.43 ; p=0.009\right)$ is in line with the SPrOO predictions. We suggest that fecundity and childlessness are dependent on the gradient of oocyte maturation reflected by mother's month of birth, which may modulate future constitution.
\end{abstract}

Seasonal reproduction is a strategy used by many species as a selective advantage that results in offspring being born at a time of year when the environment is favorable (Sliwowska et al. 2004). Month-of-birth effects have become an important topic in epidemiologic research and have been found to be related to early death from cancer or cardiovascular disease (Jansson and Mahaly 1981; Doblhammer and Vaupel 2001; Melnikov 2004). In a representative data set from Austria, the month of birth of women born in 1946-1956 and older than 45 years of age with a history of childbirth $(n=2,839)$ was also found to be associated with the number

${ }^{1}$ Department of Epidemiology and Biostatistics, Nijmegen Medical Centre, Radboud University, P.O. Box 9101, 6500 HB Nijmegen, The Netherlands.

${ }^{2}$ Research Institute of Wildlife Ecology, University of Veterinary Medicine, Vienna, Austria.

${ }^{3}$ Department of Anthropology, University of Vienna, Austria.

Human Biology, October 2007, v. 79, no. 5, pp. 479-490.

Copyright $\odot 2007$ Wayne State University Press, Detroit, Michigan 48201-1309

KEY WORDS: FECUNDITY, CHILDLESSNESS, OOCYTE MATURATION (OPTIMAL AND NONOPTIMAL), SEASONAL OPTIMAL RIPENING OOCYTE HYPOTHESIS, SEASONAL PREOVULATORY OVERRIPENESS OVOPATHY HYPOTHESIS. 
of natural liveborn children (Huber et al. 2004). Women born in summer months on average had fewer children than women born in other seasons, analogous to results found in premodern populations from the Netherlands (Smits et al. 1997a, 2001) and Canada (Lummaa and Tremblay 2003). The analysis of 388 childless women from the same Austrian data set, however, did not reveal any seasonal association.

Gonadal dysgenesis (and a range of other developmental anomalies) has been shown to be causally related to maternal overripeness of the oocyte in animals (Witschi et al. 1952; Mikamo 1968; Butcher 1981). In accordance with these basic findings, we proposed that fertilization of suboptimally matured oocytes during the breakthrough and breakdown of the ovulatory pattern causes complications of pregnancy and parturition and a continuum of constitutional diseases and reproductive weaknesses in the progeny of humans (Jongbloet 1975, 1992, 1993, 2004). In fact, women suffering from menstrual disorders, early menarche $(<11$ years of age), or early menopause ( $<40$ years of age) were disproportionately more often born during the months corresponding to the ascending and descending slopes of the birth peaks and much less often during the months corresponding to the nadirs (Jongbloet et al. 1994). This seasonal preovulatory overripeness ovopathy (SPrOO) hypothesis has also been supported by results from a study on seasonality in ectopic pregnancies (Cagnacci et al. 1999).

Dependency on month of breakthrough or breakdown of the ovulatory pattern is not directly identifiable from the month of birth, let alone remediable. However, many other transitional stages of the ovulatory pattern in which the maturation of the oocyte is at stake may well be modifiable and susceptible to health promotion, for example, adolescence and premenopause, postpartum restoration, undernutrition, endocrinological disturbances, distorted body mass index, use of neurotropic drugs, and smoking. Therefore dependency on optimal and nonoptimal ovulation rates may indicate causative links to other maternal transitional stages, for example, advanced maternal age connected with mild and severe menstrual disorders and childlessness in daughters (Smits et al. 1997b, 2002) and reduced sperm quality in sons (St. John et al. 1997). Maternal smoking, which inhibits and delays the maturation of the oocyte (Practice Committee 2004), has also been associated with early menarche and lower sperm densities (Windham et al. 2004).

The SPrOO hypothesis predicts that nonoptimal maturation of the oocyte, which coincides with the transitional stages of the ovulatory pattern, compromises the expression of the fetal genome and thus results in pathologic conditions. In contrast, the seasonally bound optimal ripening of the oocyte (SOptRO) hypothesis predicts that optimal maturation of the oocyte, which coincides with the zenith of the ovulatory seasons, guarantees optimal realization and expression of the fetal genome and thus good quality of progeny. The two hypotheses are complementary, but they are based on one and the same fluctuation of the ovulatory pattern, which can be broken down into SPrOO and SOptRO months. The aim of this study is to show that, starting from the same data set in Austria and in cooperation with some 
of the original investigators, both the potential of giving birth to more liveborn children and the lack of it are related to SOptRO and SPrOO, respectively.

\section{Definition of Prime and Minor SOptRO Months and High-Risk, No-Risk, and Very Low Risk SPrOO Months}

Seasonal breeding is the rule in feral animals, but it is dampened in domestic animals, such as rats, dogs, and cats. The breakthrough and breakdown stages of the ovulatory pattern in mammals are characterized by low or intermediate estrogen and progesterone levels and by protraction of the preovulatory (maturing) phase of the oocyte (Freedman et al. 1979; Snyder et al. 1979). In nonhuman primates the levels of luteinizing hormone (LH) increase and decrease during the transitions into the breeding and nonbreeding seasons (Walker et al. 1984; Nozaki et al. 1995). This phase is highly critical for the formation and maintenance of the genome in gametes and early embryos. The inherent pathophysiologic processes and pleiotropic consequences depend on the degree of molecular, biochemical, and physiological processes, which encompass both nuclear and cytoplasm constituents (Witschi et al. 1952; Mikamo 1968; Butcher 1981).

Fluctuations in the ovulatory rate in humans have been substantiated by indirect evidence. Some women are presumed to be more sensitive to seasonal cues (seasonal conceivers), as reflected worldwide in the birth distributions of human populations (Lam and Miron 1987; Roenneberg and Aschoff 1990) and in studies addressing fecundity in premodern women in the Netherlands (Smits et al. 1997a, 2001) and Canada (Lummaa and Tremblay 2003). These fluctuations led us to search for an arbitrary definition of the seasonally bound optimal ovulation rate corresponding to the prime SOptRO months and the nonoptimal ovulation rate corresponding to the minor SOptRO months. Three peak months of the reference birth distribution in Europe-February, March, and April—and a minor peak in September were presumed to correspond to optimal ovulations and were delineated as prime SOptRO months. The eight remaining months were defined as minor SOptRO months (see Figure 1).

By the same reasoning, the zeniths of the birth surges (March and September) were delineated as no-risk SPrOO months. The ascending and descending slopes of the major (January-February and April-May) and minor (August and October) reference birth peaks were delineated as high-risk SPrOO months, because they correspond with less optimal ovulations during the transitional stages. Eventually, the birth troughs (June-July and November-December) at the conjunction of the slopes of the reference birth curve were defined as very high risk SPrOO months because they correspond to strong concentrations of compromised oocytes. After surpassing a certain threshold, these compromised oocytes may result in deficient implantation, developmental arrest, and inherent loss of damaged embryos and fetuses before term. This distortion by differential prenatal loss, leading to an inverted dose-response gradient was evidenced by decreased secondary sex ratios in combination with increased perinatal mortality (Jongbloet 2004). This 

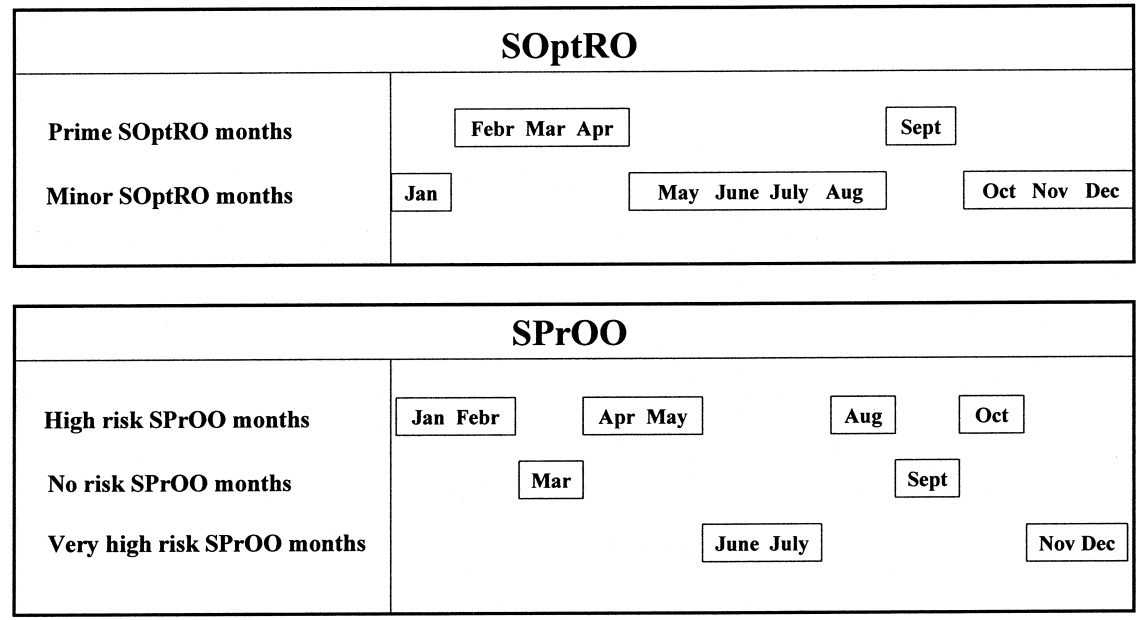

Figure 1. Schematic representation of the arbitrary definition of the prime and minor SOptRO months and of the high-risk, no-risk, and very high risk SPrOO months based on a priori knowledge of ovulatory and anovulatory seasons in mammals that correspond to the month of birth distribution in the total population, Austria, 1946-1956.

dose-response fallacy appears to be the crux of the SPrOO predictions, comparable to reverse causation by genetic determinants causing selective early death in genetic epidemiology (Davey Smith and Ebrahim 2004).

As is evident from Figure 1, the definition of February and April as both prime SOptRO and high-risk SPrOO months may seem contradictory. However, as we learned from reproductive physiology in mammals and particularly nonhuman primates (Walker et al. 1984; Nozaki et al. 1995; Shideler et al. 2001), the numbers of sound progeny conceived during the ovulatory seasons (SOptRO) and of pathological progeny during the transitional stages (SPrOO) also depend on other factors, such as maternal age, body weight, and climatological determinants. These factors may shift the birth curves several days or weeks. Therefore optimal and nonoptimal conceptions are not strictly restricted to specific months. That means that the intersecting months correspond to a mixture of optimal (SOptRO) and nonoptimal (SPrOO) conceptions.

\section{Materials and Methods}

For details on the recruitment of mothers with three or more children $(N=$ $899)$ and of childless women $(N=388)$, born in 1946-1956 and older than 45 years of age, we refer to the original paper (Huber et al. 2004). The definition of childless women was all individuals of the sample who had no birth until the third quarter of 2001 (time of survey). There was no information about the causes of childlessness. The data were collected in 25,000 households representing a $1 \%$ 
sample of the Austrian population extracted by the Microcensus Austria 2001 on Family Survey (Statistik Austria Microcensus 2001; Huber et al. 2004). To assess the peaks and troughs in the ovulation rate in Austria during the corresponding years, we used the numbers of female births per month in 1945-1956 ( $N=$ $592,544)$ from the Central Bureau for Statistics in Vienna. These numbers were corrected for length of month (average $=30.437$ days), indexed to an average of 100 births per month, and, to avoid small irregularities in the graphical representation, transformed to moving averages $\left[(a+2 b+c) / 4=b^{\prime}\right]$. The reference total birth curve for Austria (see Figures 2 and 3 ) is characterized by one major peak in winter (February-March), a decrease in spring and summer (June-August), a minor peak in September, and a deficit in autumn (October-December), which approximates the birth curve configurations in other European countries (Lam and Miron 1987; Roenneberg and Aschoff 1990).

The observed numbers of women with three or more children and of women without children were classified per month of birth and are graphically represented in Figures 2 and 3, respectively. Under the assumption that the frequencies of high fecundity and childlessness are equal in each month (null hypothesis), we calculated the expected numbers per month using the following formula:

(Expected number of women born in month $i$ )

$=($ total number of births in month $i) \frac{\text { (total number of women) }}{\text { (all births in all months) }}$.

The standard error bars for both the total birth curve and the index birth curves were added to assess the amount of variability relative to the curves' magnitudes.

The tests for seasonal cyclicity of births (harmonic or cosinor analysis with periodicity of 12 or 6 months) are not appropriate to evaluate the predicted excesses and deficits of SOptRO and SPrOO births in specific months across the year. Instead, we used conventional chi-square analyses (one-sided) for the women with three or more children to compare observed versus expected numbers born during prime versus minor SOptRO months, as defined earlier (see Figure 1). For the childless women a linear trend was evaluated for the births during the highrisk, no-risk, and very high risk SPrOO months. In addition, we estimated relative risks with $95 \%$ confidence intervals $(95 \% \mathrm{CI})$ for women born during the prime versus minor SOptRO months and for women born during the high-risk and very high risk months versus the no-risk SPrOO months, as well as during the high-risk versus very high risk SPrOO months.

\section{Results}

Women with Three or More Children and the SOptRO Predictions. The graphical representation of the relative birth frequency of women with three or more children $(n=899)$ compared with those of the population at risk (see Figure 2) illustrates birth excesses during the prime SOptRO months (February-April and September) and deficits during most of the remaining minor SOptRO months 


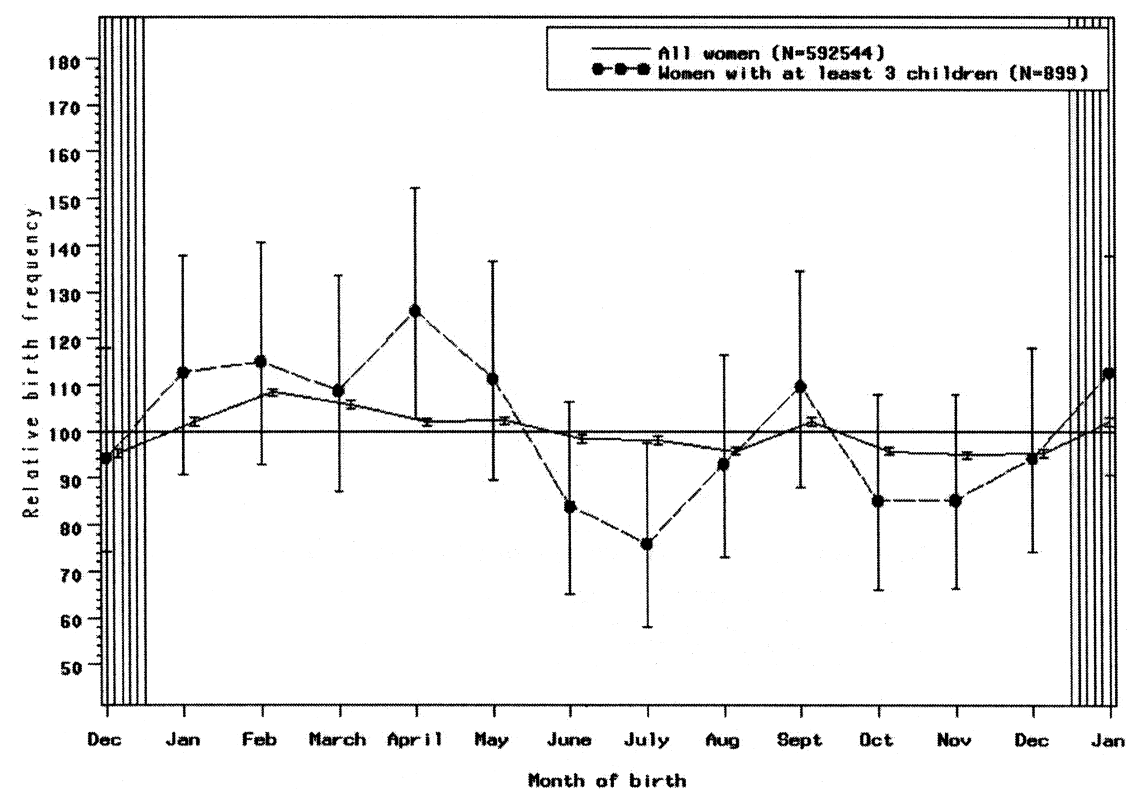

Figure 2. Comparison of the indexed birth frequencies of reproducing women with three or more children and of total of female births in Austria, 1946-1956 $(N=5,922,544)$ with the standard error bars for the total birth curve and exposure groups.

(Table 1). Comparison of observed versus expected number of births per month throughout the year does not reach statistical significance $\left(\chi^{2}=12.88 ; p=0.30\right)$, but the comparison of births during prime versus minor SOptRO months does $\left(\chi^{2}\right.$ $=2.81 ; p=0.045$, one-sided). The relative risk for mothers with three or more children born in the prime versus minor SOptRO months is 1.16 (95\% CI $=1.01-$ 1.33). These results are in line with the SOptRO predictions (see Table 1).

Childless Women and the SPrOO Predictions. The graphical representation of the indexed birth months of childless women in relation to the total birth distribution (Figure 3) illustrates that birth excesses in February and April correspond to the breakthrough and breakdown stages related to the major birth peak and that birth excesses in August and October are related to the minor birth peak (Table 2). The number of childless women born in March and September, that is, in the no-risk SPrOO months, corresponds to the presumed optimal ovulation rate. The apparent birth deficits of childless women in June-July and November-December, that is, in the very high risk SPrOO months, correspond to the birth troughs and can be interpreted as a dose-response inversion resulting from early death of the mother between birth and 45 years of age caused by nonoptimal conceptions. Comparison of observed versus expected numbers of childless women per month throughout 
Table 1. Observed and Expected Numbers, $p$ Values, and Relative Risks for Women with Three or More Children Born in the Prime Compared to the Minor SOptRO Months

\begin{tabular}{lccccccc} 
Period & $\begin{array}{c}\text { Observed } \\
\text { Number }\end{array}$ & $\begin{array}{c}\text { Expected } \\
\text { Number }\end{array}$ & $\chi^{2}$ & $\begin{array}{c}p \text { Value } \\
\text { (One- } \\
\text { Sided) }\end{array}$ & $\begin{array}{c}\text { Number of } \\
\text { Female Births } \\
\text { in Austria }\end{array}$ & $\begin{array}{c}\text { Three or More } \\
\text { Children }\end{array}$ & Relative Risk \\
\hline $\begin{array}{l}\text { Four prime } \\
\text { SOptRO } \\
\text { months }\end{array}$ & 337 & 313.09 & 1.83 & & 202,143 & $1.67 \times 10^{-3}$ & $1.16(1.01-1.33)$ \\
$\begin{array}{l}\text { Eight minor } \\
\text { SOptRO } \\
\text { months }\end{array}$ & 562 & 585.91 & 0.98 & & 390,400 & $1.44 \times 10^{-3}$ & 1.00 \\
\hline
\end{tabular}

the year again does not reach statistical significance $\left(\chi^{2}=13.87 ; p=0.24\right)$, but the linear trend from high-risk to no-risk and very high risk SPrOO months renders $\chi^{2}=8.43$ ( $p=0.009$, one-sided). The relative risk for childlessness when the mother is born in high-risk versus no-risk SPrOO months is $1.18(95 \% \mathrm{CI}=$ 0.89-1.55), and the relative risk for childlessness when the mother is born in the very high risk versus no-risk SPrOO months is 0.84 (95\% CI $=0.61-1.14)$. The relative risk for women born during the high-risk versus very high risk SPrOO months is $1.41(95 \% \mathrm{CI}=1.11-1.78)$ (see Table 2$)$. These results are in line with the SPrOO predictions, including dose-response inversion.

\section{Discussion}

This study in a representative data set from contemporary women in Austria illustrates the diversification of the SOptRO and SPrOO effects. The statistical analyses may be insufficient to fully establish causality related to the quality of the oocyte, but the graphical representations are of particular interest.

High fecundity (greater than three children) appears to be more frequent in women born during the a priori determined SOptRO months (February-April and September), which correspond to the presumed optimal ovulation rate, and less frequent in women born during the remaining minor SOptRO months, which correspond to the presumed nonoptimal ovulation rates (see Figure 2). This is concordant with the original results of Huber et al. (2004), which were related to the total number of liveborn children. In addition, our results are in accordance with three other studies addressing fecundity in premodern women in the Netherlands (Smits et al. 1997a, 2001) and Canada (Lummaa and Tremblay 2003). In the Canadian study the larger number of women surviving to reproductive age and raising at least one child to adulthood (reproductive fitness) coincided with the major (February) and minor (September) birth peaks of the population at risk; the smaller number of such women coincided with the birth troughs in July and October-November. In addition, similar SOptRO effects were present for other 


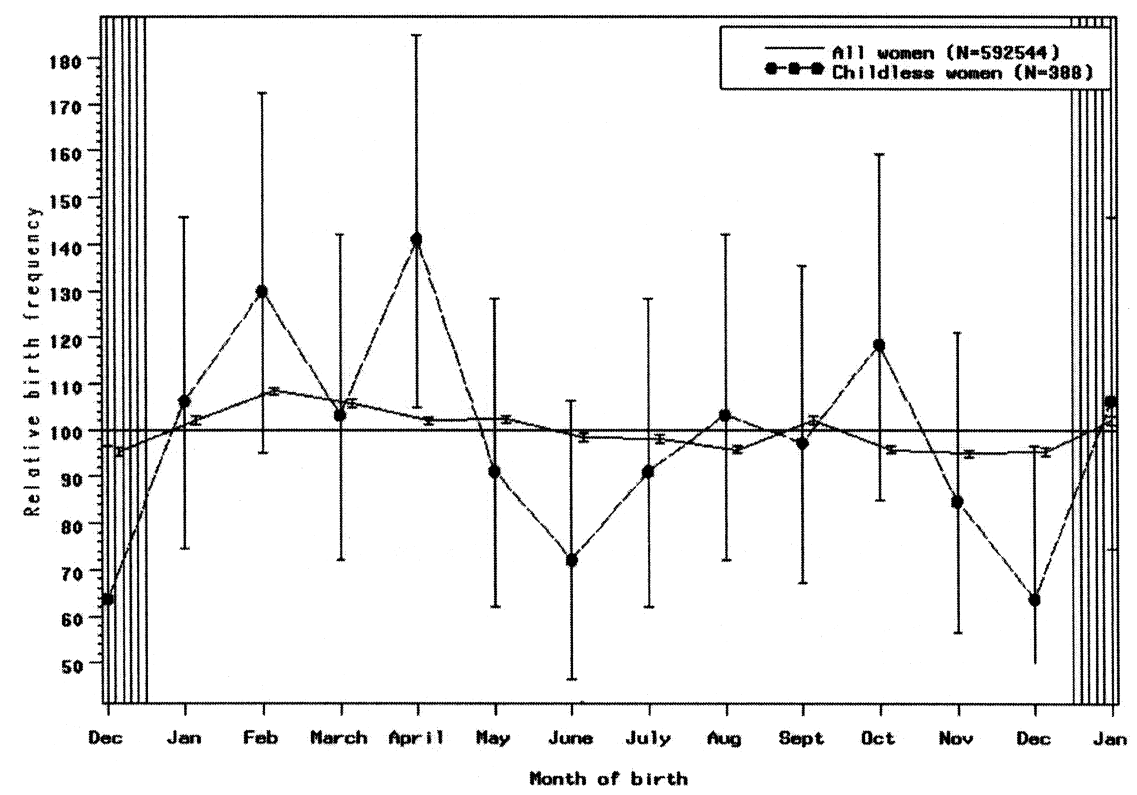

Figure 3. Comparison of the indexed birth frequencies of childless women and of the total births in Austria, 1946-1956 $(N=592,544)$ with the standard error bars for the total birth curve and exposure groups.

determinants of optimal constitution, such as birth weight and length (Noack and Otto 1957; Selvin and Janerich 1971; Matsuda et al. 1995; Wohlfahrt et al. 1998), teenage and adult stature (Henneberg and Louw 1993; Weber et al. 1998), eminence (Huntington 1938a, 1938b), and longevity (Jongbloet 1992).

The results among childless women are also in line with previous month-ofbirth studies related to subfecundity traits (Jongbloet 1993; Jongbloet et al. 1994; Smits et al. 1997a, 1997b). The double-hump surge as amplification at the major birth peak is prominent, and an indication of it is seen at the minor birth peak (see Figure 3). This is a hallmark of the SPrOO configuration, which was also present among women with ectopic pregnancies (Cagnacci et al. 1999), preterm births (Rantakallio 1971), perinatal mortality (Rantakallio 1971; Jongbloet 2004), and several developmental anomalies in offspring, for example, anencephaly and Down and Turner syndromes (Jongbloet 1975). In addition, the double-hump surge was also related to constitutional diseases, such as menstrual disorders (Jongbloet et al. 1994), schizophrenia (Pallast et al. 1994), diabetes mellitus type 1 (Jongbloet et al. 1998), and eating disorders (Jongbloet et al. 2005). Menstrual disorders, longer time to pregnancy, stillbirth, and childlessness are also dependent on other transitional stages of maternal reproductive life, such as postpartum restoration of the ovulatory pattern and advanced maternal age (Smits et al. 1997b, 2000). 
Table 2. Observed and Expected Numbers, $p$ Values, and Relative Risks for Childless Women Born in the High-Risk Versus No-Risk and Very High Risk Versus No-Risk SPrOO Months

\begin{tabular}{lccccccc} 
Period & $\begin{array}{c}\text { Observed } \\
\text { Number }\end{array}$ & $\begin{array}{c}\text { Expected } \\
\text { Number }\end{array}$ & $\chi^{2}$ & $\begin{array}{c}p \text { Value } \\
\text { (One- } \\
\text { Sided })\end{array}$ & $\begin{array}{c}\text { Number of } \\
\text { Female Births } \\
\text { in Austria }\end{array}$ & $\begin{array}{c}\text { "Risk" of } \\
\text { Childlessness }\end{array}$ & Relative Risk \\
\hline $\begin{array}{l}\text { Six high-risk } \\
\begin{array}{l}\text { SOptRO } \\
\text { months }\end{array}\end{array}$ & 222 & 195.88 & 3.48 & & 298,342 & $7.44 \times 10^{-4}$ & $1.18(0.89-1.55)$ \\
$\begin{array}{l}\text { Two no-risk } \\
\text { SOptRO } \\
\text { months }\end{array}$ & 65 & 67.16 & 0.07 & & 102,862 & $6.32 \times 10^{-4}$ & 1.00 \\
$\begin{array}{l}\text { Four very } \\
\text { high risk }\end{array}$ & 101 & 124.96 & 4.59 & & 191,339 & $5.28 \times 10^{-4}$ & $0.84(0.61-1.14)$ \\
$\begin{array}{l}\text { SOptRO } \\
\text { months }\end{array}$ & & & & & & & \\
$\begin{array}{c}\text { Linear by } \\
\text { linear } \\
\text { trend }\end{array}$ & & & & & & & \\
\hline
\end{tabular}

Several limitations related to the definitions and the representativeness of this study population should be considered. First, there are different possibilities for misclassification, for example, the use of time of birth as a proxy for time of conception. It should be noted that short and long pregnancy durations are also seasonal (Rantakallio 1971). This type of seasonality may underestimate the strength of the associations. Another reason for misclassification is the arbitrary delineation of the prime versus minor SOptRO months and of the high-risk, no-risk, and very high risk SPrOO months used in this study. As mentioned earlier, any delineation is only an approximation of the seasonal variation in oocyte quality and quantity. There is overlap in the adjacent months that impedes meticulous determination of the seasons addressed, particularly during the transitions from ovulatory to anovulatory seasons and vice versa. As a consequence, the intersecting months correspond with a mixture of optimally (SOptRO) and nonoptimally (SPrOO) matured oocytes, which results in dilution of the graphical and statistical findings.

Second, the number of women in our target population was restricted. This was partly due to the limitation of our data set to $1 \%$ of the Austrian family survey (1946-1956) and particularly to survival bias resulting from absence of women who died before completion of their reproductive life, that is, before their 46th birthday. This possibility of selective mortality may be important because both early menopause and childlessness are known to be associated with all-cause mortality resulting from comorbidity (Jacobson et al. 2003; Mondul et al. 2005). In contrast, offspring survival, longevity, and lifetime reproductive success (total number of offspring surviving to 2 years of age) are correlated with different components of fitness (Kruuk et al. 1999; Lummaa 2003). Unfortunately, we were 
unable to substantiate the amount of early death in our population because the numbers of deceased women born in 1946-1956 and the dates of their marriages were not available.

Third, family planning to deliver in certain months may have played a role in this Austrian sample, although we have no evidence to support this assumption. In addition, normal and high fecundity are not restricted to women with three or more children, whereas childlessness may have consciously been intended or been due to paternal infertility. Our results related to women with three or more children, however, do not differ substantially from those in premodern societies without contraceptive facilities (Smits et al. 1997a, 2001; Lummaa and Tremblay 2003). Fecundability, ovarian dysgenesis, and premature ovarian failure may also be determined by genetic factors, for example, fragile X (FMR1) (Sullivan et al. 2005), or by other pre- and postconceptionally acting reproduction-toxic factors, such as irradiation, smoking, toxic agents, and infections. In addition, seasonality of birth may interact with impaired ovarian development because of other transitional stages of the ovulatory pattern, for example, maternal smoking, which inhibits and delays the maturation of the oocyte (Practice Committee 2004), or advanced maternal age, which has been associated with early menarche and lower sperm density (Smits et al. 2002). Data on these variables were not collected in the Austrian family survey, but it is hard to imagine that Mendelian inheritance or the mentioned exogenous factors could generate and mimic the intricacies of the SPrOO month-of-birth configurations during 11 consecutive years in this study population.

Summing up, these results appear to substantiate the presumptions that maturation of the oocyte is a cornerstone of constitutional well-being and lifetime reproductive fitness. This may be a stimulus for future research along these lines.

Acknowledgments Susanne Huber was supported by the Austrian Programme for Advanced Research and Technology (APART) of the Austrian Academy of Sciences.

Received 1 December 2006; revision received 1 June 2007.

\section{Literature Cited}

Butcher, R. L. 1981. Experimentally induced gametopathies. In Principles and Practice of Obstetrics and Perinatology, L. Iffy and H. A. Kaminetzky, eds. New York: Wiley, 339-349.

Cagnacci, A., S. Landi, and A. Volpe. 1999. Rhythmic variation in the rate of ectopic pregnancy throughout the year. Am. J. Obstet. Gynecol. 180:1067-1071.

Davey Smith, G., and S. Ebrahim. 2004. Mendelian randomization: Prospects, potentials, and limitations. Int. J. Epidemiol. 33:30-42.

Doblhammer, G., and J. W. Vaupel. 2001. Life span depends on month of birth. Proc. Natl. Acad. Sci. USA 98:2934-2939.

Freedman, J., M. C. Garcia, and O. J. Ginther. 1979. Influence of photoperiod and ovaries on seasonal reproductive activity in mares. Biol. Reprod. 20:567-574. 
Henneberg, M., and G. J. Louw. 1993. Further studies on the month-of-birth effect on body size: Rural schoolchildren and an animal model. Am. J. Phys. Anthropol. 91:235-244.

Huber, S., M. Fieder, B. Wallner et al. 2004. Birth month influences reproductive performance in contemporary women. Hum. Reprod. 19:1081-1082.

Huntington, E. 1938a. Genius and season. In Season of Birth, by E. Huntington. New York: Wiley, 328-348.

Huntington, E. 1938b. Leadership, birth rank, and season of birth. In Season of Birth, by E. Huntington. New York: Wiley, 290-327.

Jacobson, B. J., I. Heuch, and G. Kvåle. 2003. Age at natural menopause and all-cause mortality: A 37-year follow-up of 19,731 Norwegian women. Am. J. Epidemiol. 157:923-929.

Jansson, B., and M. A. Malahy. 1981. Cancer risk, age at diagnosis, and age at death as functions of season of birth. Cancer Detect. Prevent. 4:291-294.

Jongbloet, P. H. 1975. The effects of preovulatory overripeness of human eggs on development. In Aging Gametes: Their Biology and Pathology, R. J. Blandau, ed. Basel: Karger, 300-329.

Jongbloet, P. H. 1992. Seasonal fluctuation of pathological and optimum conceptions, maternal subfecundity, gender dimorphism, and survival. Colleg. Antropol. 16:99-107.

Jongbloet, P. H. 1993. Discrimination between two competing hypotheses on seasonality of birth in subfecundity traits. Med. Hypoth. 40:211-216.

Jongbloet, P. H. 2004. Overripeness ovopathy: A challenging hypothesis for sex ratio modulation. Hum. Reprod. 19:769-774.

Jongbloet, P. H., H. M. M. Groenewoud, R. A. Hirasing et al. 1998. Seasonality of birth in patients with childhood diabetes in the Netherlands. Diabetes Care 21:190-191.

Jongbloet, P. H., H. M. M. Groenewoud, and N. Roeleveld. 2005. Seasonally bound ovopathy versus "temperature at conception" as cause for anorexia nervosa. Int. J. Eat. Disord. 38:236-243.

Jongbloet, P. H., W. M. Kersemaekers, G. A. Zielhuis et al. 1994. Menstrual disorders and month of birth. Ann. Hum. Biol. 21:511-518.

Kruuk, L. E. B., T. H. Clutton-Brock, K. E. Rose et al. 1999. Early determinants of lifetime reproductive success differ between sexes in red deer. Proc. R. Soc. Lond. 266:1655-1661.

Lam, D. A., and J. A. Miron. 1987. The seasonality of births in human populations. Res. Rep. 114:158.

Lummaa, V. 2003. Early developmental conditions and reproductive success in humans: Downstream effects of prenatal famine, birth weight, and timing of birth. Am. J. Hum. Biol. 15:370-379.

Lummaa, V., and M. Tremblay. 2003. Month of birth predicted reproductive success and fitness in premodern Canadian women. Proc. R. Soc. Lond. B 270:2355-2361.

Matsuda, S., Y. Hiroshige, M. Furata et al. 1995. Geographic differences in seasonal variation of mean birth weight in Japan. Hum. Biol. 67:641-656.

Melnikov, V. N. 2004. Month of birth predicts lung cancer morbidity in Siberia. Epidemiology 15:645646.

Mikamo, K. 1968. Intrafollicular overripeness and teratologic development. Cytogenetics 7:212-233.

Mondul, A. M., C. Rodriguez, E. J. Jacobs et al. 2005. Age at natural menopause and all-cause mortality. Am. J. Epidemiol. 162:1089-1097.

Noack, H., and W. Otto. 1957. Statistische Untersuchungen zur Frage jahreszeitlicher Einflüsse in der Geburtshilfe unter Berücksichtigung der Neugeborenenlange. Arch. Gynäk. 188:457-473.

Nozaki, M., F. Mitsunaga, and K. Shimizu. 1995. Reproductive senescence in female Japanese monkeys (Macaca fuscata): Age- and season-related changes in hypothalamic-pituitary-ovarian functions and fecundity rates. Biol. Reprod. 52:1250-1257.

Pallast, E. G. M., P. H. Jongbloet, H. M. Straatman et al. 1994. Excess seasonality of births among patients with schizophrenia and seasonal ovopathy. Schizophr. Bull. 20:269-276.

Practice Committee, American Society for Reproductive Medicine. 2004. Smoking and infertility. Fertil. Steril. 81:1181-1186.

Rantakallio, P. 1971. The effect of a northern climate on seasonality of births and the outcome of pregnancies. Acta Paediatr. Scand. 218:51-67. 
Roenneberg, T., and J. Aschoff. 1990. Annual rhythm of human reproduction. I. Biology, sociology, or both? J. Biol. Rhythms 5:195-216.

Selvin, S., and D. T. Janerich. 1971. Four factors influencing birth weight. Br. J. Prev. Soc. Med. 25:1216.

Shideler, S. E., N. A. Gee, J. Chen et al. 2001. Estrogen and progesterone metabolites and folliclestimulating hormone in the aged Macaque female. Biol. Reprod. 65:1718-1725.

Sliwowska, J. H., H. J. Billings, R. L. Goodman et al. 2004. The premammillary hypothalamic area of the ewe: Anatomical characterization of a melatonin target are mediating seasonal reproduction. Biol. Reprod. 70:1768-1775.

Smits, L. J., P. H. Jongbloet, and G. A. Zielhuis. 2000. Fecundity of daughters born after short, intermediate, or long birth intervals: An analysis of family reconstructions from the Netherlands, late 19th-early 20th century. Soc. Biol. 47:18-33.

Smits, L. J., P. H. Jongbloet, and G. A. Zielhuis. 2001. Season of birth and reproductive performance: An analysis of family reconstructions of 500 women born in the Netherlands at the end of the 19th century. Chronobiol. Intern. 18:525-539.

Smits, L. J., F. W. A. Van Poppel, J. A. Verduin et al. 1997a. Is fecundability associated with month of birth? An analysis of 19th and early 20th century family reconstruction data from the Netherlands. Hum. Reprod. 12:2572-2578.

Smits, L. J., W. N. P. Willemsen, G. A. Zielhuis et al. 1997b. Conditions at conception and risk of menstrual disorders. Epidemiology 8:524-529.

Smits, L. J., G. A. Zielhuis, P. H. Jongbloet et al. 2002. Mother's age and daughters' fecundity: An epidemiological analysis of the late 19 th to early 20 th century family reconstructions. Int. J. Epidemiol. 31:349-358.

Snyder, D. A., D. D. Turner, F. K. Miller et al. 1979. Follicular and gonadotropic changes during transition from ovulatory to anovulatory seasons. J. Reprod. Fertil. 27(suppl.):95-101.

Statistik Austria Microcensus. 2001. Microcensus Austria 2001 on Family Survey. Third quarter. Vienna, Austria: Central Bureau of Statistics.

St. John, J. C., I. D. Cooke, and C. L. R. Barrau. 1997. Mitochondrial mutations and male infertility. Nat. Med. 3:124-125.

Sullivan, A. K., M. Marcus, M. P. Epstein et al. 2005. Association of FMR1 repeat size with ovarian dysfunction. Hum. Reprod. 20:402-412.

Walker, M. L., M. E. Wilson, and T. P. Gordon. 1984. Endocrine control of the seasonal occurrence of ovulation in rhesus monkeys housed outdoors. Endocrinology 114:1074-1081.

Weber, G. W., H. Prossinger, and H. Seidler. 1998. Height depends on month of birth. Nature 391:754755.

Windham, G. C., C. Bottomley, C. Birner et al. 2004. Age at menarche in relation to maternal use of tobacco, alcohol, coffee, and tea during pregnancy. Am. J. Epidemiol. 159:862-871.

Witschi, E., W. C. Nelson, and S. J. Segal. 1952. Genetic development and hormonal aspects of gonadal dysgenesis and sex inversion in man. J. Clin. Endocrin. 17:737-742.

Wohlfahrt, J., M. Melbye, P. Christens et al. 1998. Secular and seasonal variation of length and weight at birth. Lancet 352:1990. 